\title{
SISTEM APLIKASI DEKSTOP PERSEDIAAN SPAREPART DAN SUPPLIES PADA PT DELTA GRAFIKA COMPATINDO
}

\author{
Saiful Hamid ${ }^{1}$, Maria Cleopatra ${ }^{2}$, Noor Komari Pratiwi ${ }^{3}$ \\ ${ }^{1,2,3}$ Universitas Indraprasta PGRI \\ Jl. Raya Tengah No. 80, Kel. Gedong, Kec. Pasar Rebo, Jakarta Timur 13760, Jakarta

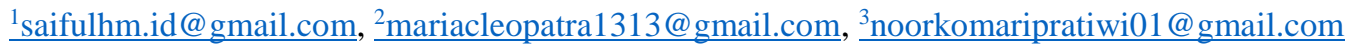

\begin{abstract}
ABSTRAK
PT Delta Grafika adalah sebuah perusahaan yang bergerak di bidang percetakan. Persediaan barang yang terdapat di perusahaan ini masih dicatat secara manual. Penelitian ini bertujuan untuk mengatasi beberapa masalah yang terjadi pada PT Delta Grafika Compatindo dalam pendataan, pembelian, dan penjualan serta pengendalian stok persediaan barang agar dapat tersusun rapi, sistematis, dan mudah dalam pelaporan. Metode penelitian yang digunakan adalah penelitian kualitatif dengan metode studi lapangan untuk pengambilan data, yaitu melalui pengamatan langsung, wawancara dengan pihak terkait, serta melakukan dokumentasi untuk mendapatkan informasi yang dibutuhkan. Dalam penelitian ini metode pengembangan sistem menggunakan metode Waterfall. Hasil dari penelitian ini adalah seperangkat aplikasi yang dikembangkan menggunakan bahasa pemrograman Java NetBeans IDE 8.2 dan database MySQL yang digunakan untuk penyimpanan data. Perancangan sistem yang digunakan oleh peneliti sebagai alat bantu dalam membangun sistem ini adalah Diagram Aliran Data (DAD) Konteks, Nol, dan Rinci. Sistem aplikasi yang dirancang ini dapat membantu dan mempermudah karyawan PT Delta Grafika Compatindo dalam pendataan, pembelian, dan penjualan serta pengendalian stok persediaan barang agar dapat tersusun rapi, sistematis, dan mudah dalam pelaporan.
\end{abstract}

Kata Kunci: Persediaan, Plotter, Sistem, Sparepart, Supplies

\begin{abstract}
PT Delta Graphics is a company engaged in the printing sector. The company's existing inventory is still recorded manually. The purpose of this study is to overcome the problems that occur at PT Delta Graphic Compatindo in data collection, purchasing, and sales as well as controlling the stock of goods so that they can be arranged neatly, systematically, and easily in reporting. The research method used is qualitative research with field study methods for data collection, namely through direct observation, interviews with related parties, and conducting documentation to obtain the required information. In this study, the system development method uses the Waterfall method. The result of this research is a set of applications developed using the Java NetBeans IDE 8.2 programming language and MySQL database used for data storage. The design of the system used by researchers as a tool in building this system is a Context, Zero, and Detailed Data Flow Diagram (DAD). This application system designed can help and make it easier for PT Delta Graphic Compatindo employees in data collection, purchasing, and sales as well as inventory control so that they can be arranged neatly, systematically, and easily in reporting.
\end{abstract}

Key Word: Inventory, Plotter, Sparepart, Supplies, System

\section{PENDAHULUAN}

Saat ini perkembangan teknologi di Indonesia mengalami perubahan sangat pesat. Kecanggihan dan kemajuan teknologi berdampak cukup kuat terhadap berkembangnya aktivitas bisnis terutama pada jasa percetakan (Adhari, 2020).

PT Delta Grafika Compatindo yang bergerak dalam bidang percetakan menggunakan mesin plotter sebagai bisnis utama. Plotter merupakan printer grafis serta perangkat keluaran pertama yang dapat mencetak gambar berukuran sebesar gambar arsitektur dan engineering (Yahfizham, 2019).

Untuk operasional, plotter membutuhkan supplies seperti tinta dan kertas sebagai media cetaknya. Ketika mesin plotter mengalami kendala, perlu dilakukan perbaikan dan juga pergantian sparepart. Secara umum, sparepart (suku cadang) terdiri dari suku cadang baru, yaitu komponen yang belum pernah dipakai sebelumnya kecuali pada saat melakukan percobaan atau tes (masih dalam kondisi baru), dan suku cadang bekas, yaitu komponen yang sebelumnya pernah dipakai 
dalam kurun waktu tertentu. Terdapat dua kondisi berbeda pada suku cadang bekas, yaitu kondisi masih layak pakai, secara teknis komponen masih dapat dipergunakan atau diasumsikan masih memiliki sisa umur pakai, dan kondisi tidak layak pakai, secara teknis komponen sudah tidak dapat lagi dipakai walaupun sudah diperbaiki (Hengki, 2017).

Aktivitas usaha yang dilakukan pada PT Delta Grafika Compatindo adalah jual beli mesin plotter, printer, supplies, dan sparepart. Masalah utama yang dihadapi adalah pendataan semua barang masih belum terkomputerisasi sepenuhnya. Banyak data supplies dan sparepart hanya ditulis serta dihapus secara manual pada kertas $h v s$ yang membuat perhitungan dalam jangka panjang tidak begitu akurat.

Masalah berikutnya adalah pembuatan laporan penjualan dan pembelian masih dilakukan secara manual pada Microsoft Excel. Hal tersebut memakan waktu lebih lama karena semua data barang, pelanggan, supplier, dan harga barang masih belum tersimpan dalam database.

Tujuan dari penelitian ini adalah merancang aplikasi yang mampu memudahkan karyawan bagian stok dan admin untuk mengolah data serta mencetak berbagai laporan dengan lebih akurat dan efisien.

Sistem adalah suatu kelompok unsur yang memiliki hubungan erat satu sama lain yang berfungsi bersama-sama dalam mencapai tujuan tertentu (Sutabri, 2012).

Aplikasi desktop adalah suatu aplikasi yang berisikan sebuah instruksi standar dan sekumpulan aturan sintaks serta semantik yang digunakan secara khusus untuk menjelaskan program komputer berbentuk offline atau aplikasi yang dapat dioperasikan secara offline sehingga dapat berjalan sendiri tanpa adanya internet yang terhubung pada komputer, akan tetapi kita diharuskan untuk menginstalnya sendiri di komputer ataupun laptop kita (Iskandar et al., 2020).

Sementara itu, persediaan (inventory) ialah barang dagangan utama yang saat ini dimiliki perusahaan. Persediaan (inventory) merupakan stock atau simpanan barang- barang yang disimpan oleh perusahaan dalam persediaan yang berkaitan dengan bisnis yang dijalankan. Secara umum, istilah persediaan digunakan untuk menunjukkan barang-barang yang dimiliki untuk keperluan dijual kembali atau digunakan untuk memproduksi barangbarang yang akan dijual. Dalam perusahaan dagang, persediaan adalah barang-barang yang bisa diperoleh atau dibeli dengan maksud untuk dijual kembali tanpa perlu mengubah barang itu sendiri (Stevenson \& Chuong, 2013).

Berdasarkan penjelasan di atas, dirancanglah sistem aplikasi dekstop persediaan sparepart dan supplies pada PT Delta Grafika Compatindo. Dengan menggunakan sistem aplikasi ini, karyawan bagian stok dan admin menjadi lebih mudah dalam mengolah data serta mencetak berbagai laporan dengan akurat dan efisien.

Hal ini sesuai dengan hasil penelitian yang menyimpulkan bahwa aplikasi persediaan barang dan transaksi penjualan mampu memudahkan pemilik dalam mengelola datadata persediaan barang serta membantu kasir melayani transaksi (Ramadhani et al., 2017).

\section{METODE PENELITIAN}

Metode penelitian yang digunakan ialah metode penelitian kualitatif. Penelitian kualitatif merupakan penelitian yang tidak menggunakan model-model matematik, statistik maupun komputer. Proses penelitian ini dimulai dari penyusunan asumsi dasar dan aturan berpikir yang nantinya akan digunakan dalam penelitian. Dalam penelitian kualitatif, kegiatan yang dilakukan peneliti tidak menggunakan angka ketika pengumpulan data penelitian dan juga dalam menampilkan penafsiran terhadap hasilnya (Mamik, 2015).

Dalam mengembangkan sistem aplikasi persediaan ini, pengembangan model waterfall adalah metode yang digunakan penulis. Model waterfall menampilkan pendekatan alur hidup software secara urut dimulai dari analisis, desain, pengkodean, pengujian, hingga tahap support (Sukamto \& Shalahuddin, 2011).

Tempat penelitian dalam proses pengumpulan data yang menunjang penelitian ini bertempat di PT Delta Grafika Compatindo yang 
beralamat di Jalan Cipulir V No. 15 RT 01/ RW 08, Kebayoran Lama, Jakarta Selatan dimulai selama 5 bulan pada bulan Maret tahun 2021 sampai dengan bulan Juli tahun 2021.

\section{HASIL DAN PEMBAHASAN}

Berdasarkan hasil pengamatan, peneliti mengidentifikasi masalah dari sistem pengelolaan data di antaranya sebagai berikut.

1. Data persediaan part dan supplies masih dicatat secara manual pada kertas sehingga tidak akurat dalam jangka panjang.

2. Data pelanggan dan supplier tidak dikelola dengan benar, hanya copy paste dari dokumen sebelumnya atau harus bertanya kepada pelanggan dan supplier terlebih dahulu.

3. Format pembuatan laporan tidak konsisten dan efisien.

Berdasarkan masalah yang terdapat pada PT Delta Grafika Compatindo tersebut, penulis memberikan beberapa alternatif penyelesaian masalah.

1. Pembuatan aplikasi dekstop yang mengelola data ketersediaan sparepart dan supplies supaya pendataan lebih efektif.

2. Menggunakan database $M y S Q L$ sebagai media pendataan sparepart, supplies, supplier, dan customer.

3. Menggunakan plugin iReport yang terdapat pada Neatbeans dalam pembuatan laporan yang sudah terhubung dengan aplikasi supaya pembuatan laporan menjadi lebih mudah dan efisien. Penggunaan iReport mengurangi kesalahan data karena sudah diambil dari database.

\section{Diagram Konteks}

Diagram konteks dapat mewakili dan menggambarkan segala proses yang berada di dalam sistem tertentu. Merupakan tingkatan yang paling tinggi dalam diagram alir data (DAD), sering kali diberikan nomor nol (0) (Muslihudin \& others, 2016).

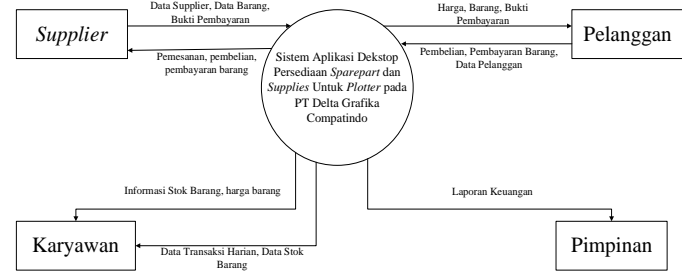

Gambar 1. Diagram Konteks

\section{Diagram Nol}

Diagram nol menampilkan sistem sesuai dengan banyak proses yang terjadi di dalam sistem dan merupakan turunan dari diagram konteks. Pada diagram ini penyimpanan data akan dimuat (Muslihudin \& others, 2016).

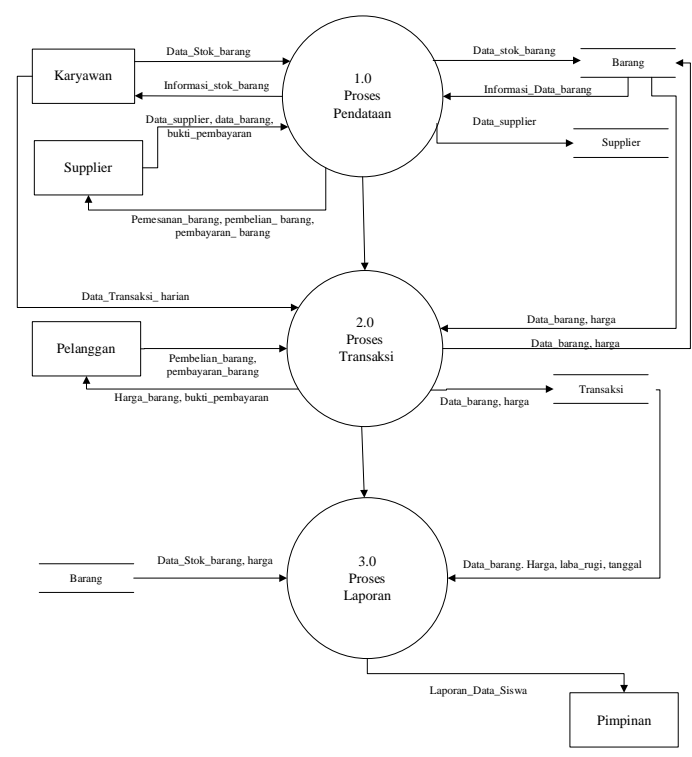

Gambar 2. Diagram Nol

\section{Entity Relationship Diagram (ERD)}

ERD bisa diibaratkan data konseptual yang biasa digunakan dalam proses untuk mengembangkan basis data dengan tipe relasional (Lubis, 2016).

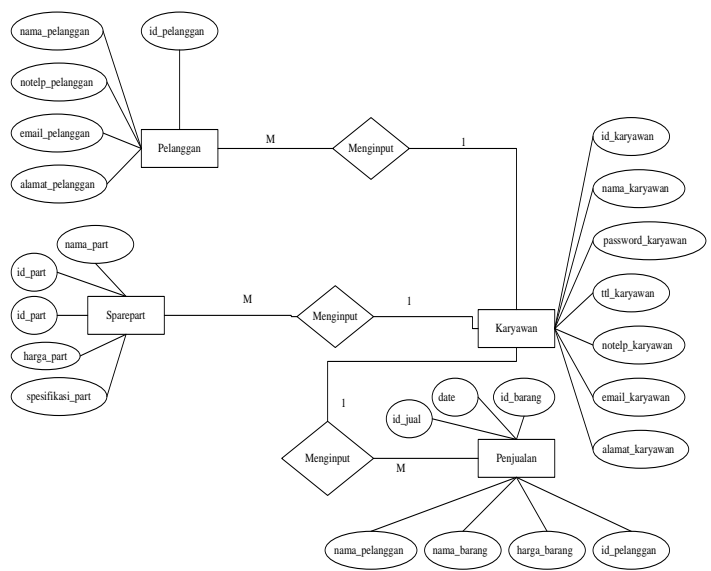

Gambar 3. ERD 


\section{Normalisasi}

Normalisasi merupakan suatu teknik untuk mendesain tabel basis data relasional agar duplikasi data dapat dikurangi, sehingga bisa menjaga basis data dari permasalahan unomaly update (Pahlevi, 2013).

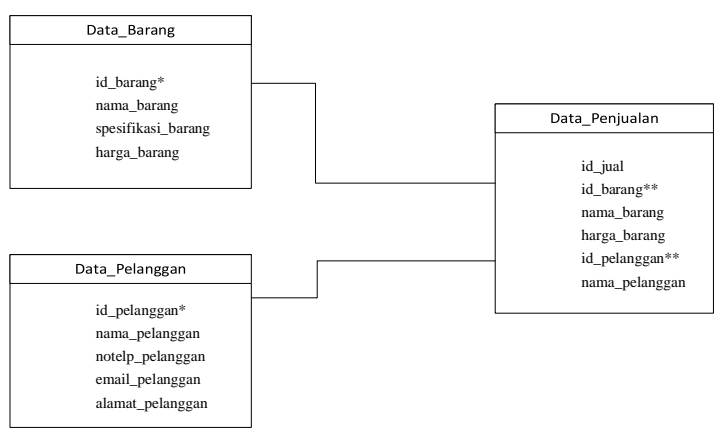

Gambar 4. Normalisasi

\section{Tampilan Layar Sistem}

Tampilan Layar Login

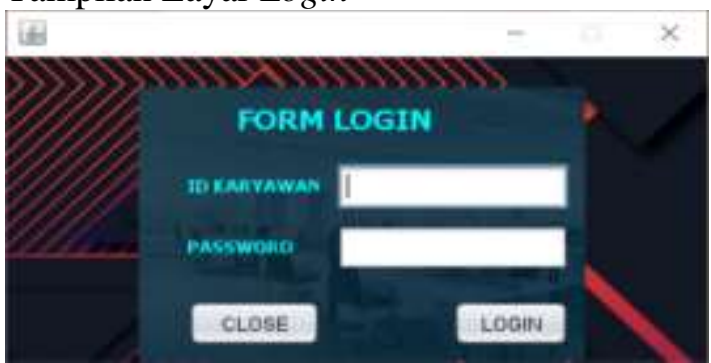

Gambar 4. Tampilan Layar Login

Tampilan ini digunakan sebagai tampilan awal sebelum mengakses keseluruhan aplikasi supaya tetap terjaga dengan baik kerahasiaannya.

\section{Tampilan Layar Form Pelanggan}

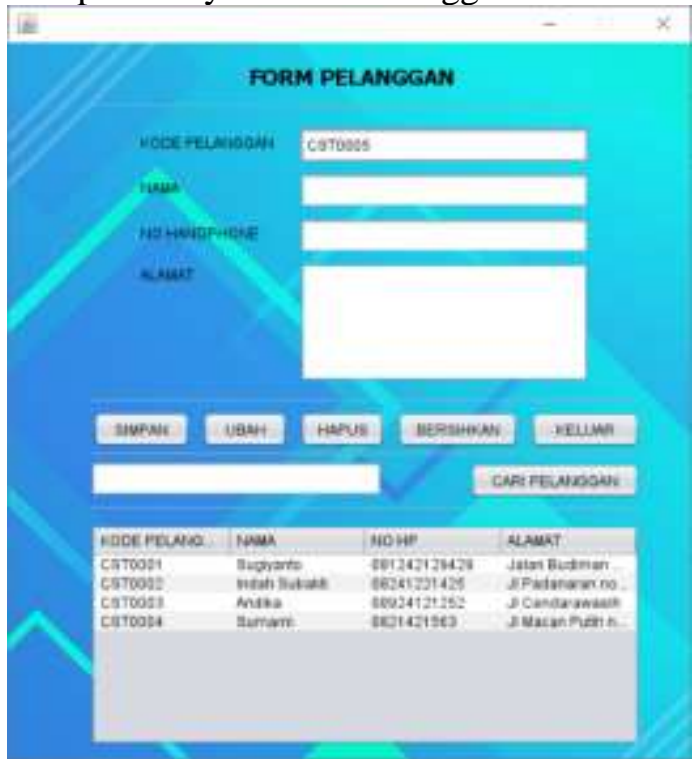

Gambar 5. Tampilan Layar Form Pelanggan
Pada form ini setiap ada pelanggan baru maka data akan ditambahkan. Data pelanggan nantinya digunakan untuk transaksi penjualan agar tidak perlu memasukkan data kembali.

Tampilan Layar Form Supplier

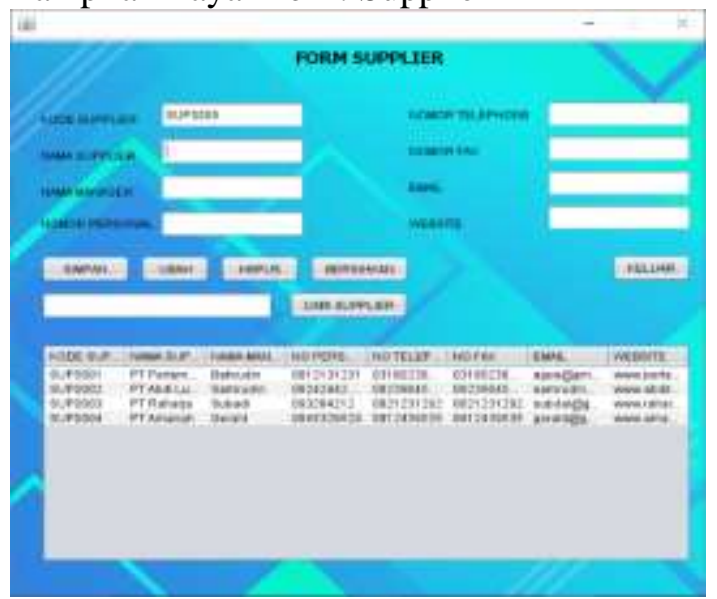

Gambar 6. Tampilan Layar Form Supplier

Pada form ini, data supplier yang menyediakan berbagai mesin plotter, supplies, dan sparepart akan ditambahkan dalam database. Ketika melakukan restock hanya perlu melihat data kembali.

Tampilan Layar Form Barang

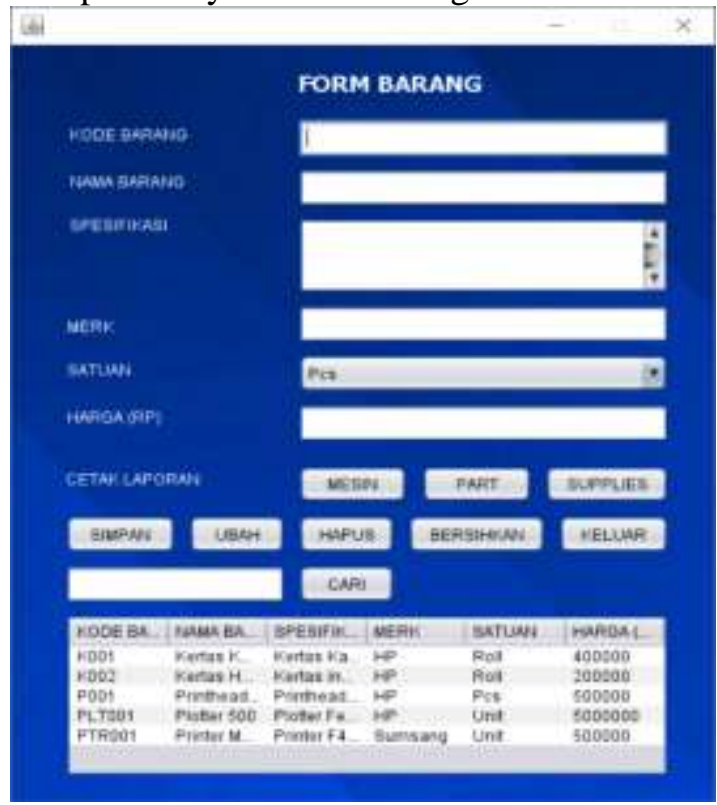

Gambar 7. Tampilan Layar Form Barang

Pada form ini semua barang akan di data. Pembagian jenis barang dipisahkan menggunakan kode yang berbeda pada setiap awalannya untuk memudahkan mencari dan mengingat. Untuk itu pemberian kode dibuat secara manual. Untuk pembuatan laporan 
dipisahkan menjadi 3 bagian, antara mesin plotter, sparepart, dan juga supplies.

Tampilan Layar Form Transaksi Penjualan

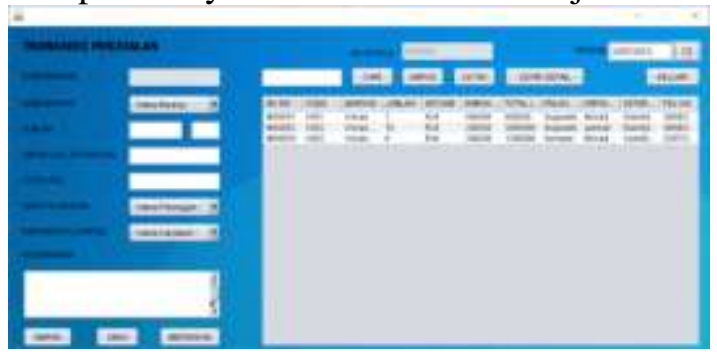

Gambar 8. Tampilan Layar Form Transaksi Penjualan

Pada form ini dilakukan transaksi penjualan kepada customer. Nomor invoice akan tercetak otomatis. Nama dan kode barang akan diambil dari database yang sudah dimasukkan sebelumnya sehingga harga barang juga akan terisi otomatis. Dengan mengetikkan jumlah barang maka total harga akan terhitung secara otomatis. Nama pelanggan dan karyawan juga tersedia dalam menu drowdown yang akan digunakan untuk permintaan tanda tangan pada lembar invoice. Pada form ini laporan bisa dicetak untuk semua transaksi (rekap \& satuan).

Tampilan Layar Form Transaksi Pembelian

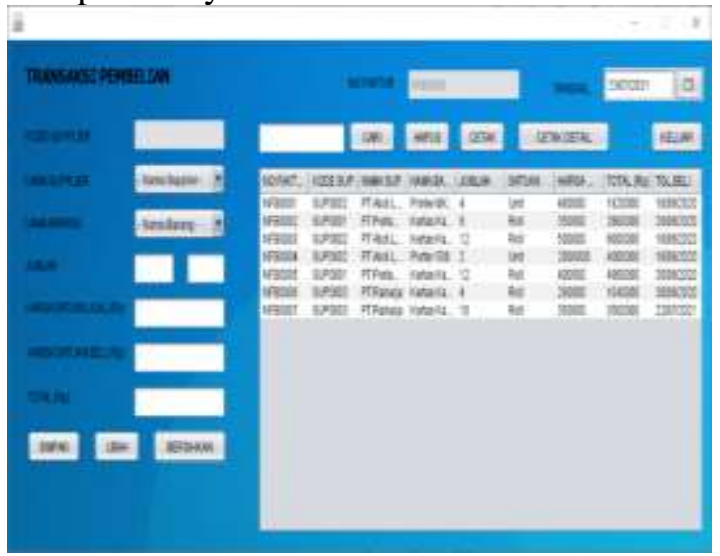

Gambar 9. Tampilan Layar Form Transaksi Pembelian

Pada form ini setiap transaksi dapat dicetak untuk diajukan kepada supplier sebagai dokumen purchase order agar barang bisa disiapkan dan diantarkan ke kantor atau karyawan kami yang mengambil barang tersebut ke tempat supplier. Data barang dan supplier diambil dari database. Penjumlahan harga total sudah terkalkulasi otomatis tanpa perlu melakukan klik tombol hitung.
Tampilan Layar Laporan Data Mesin

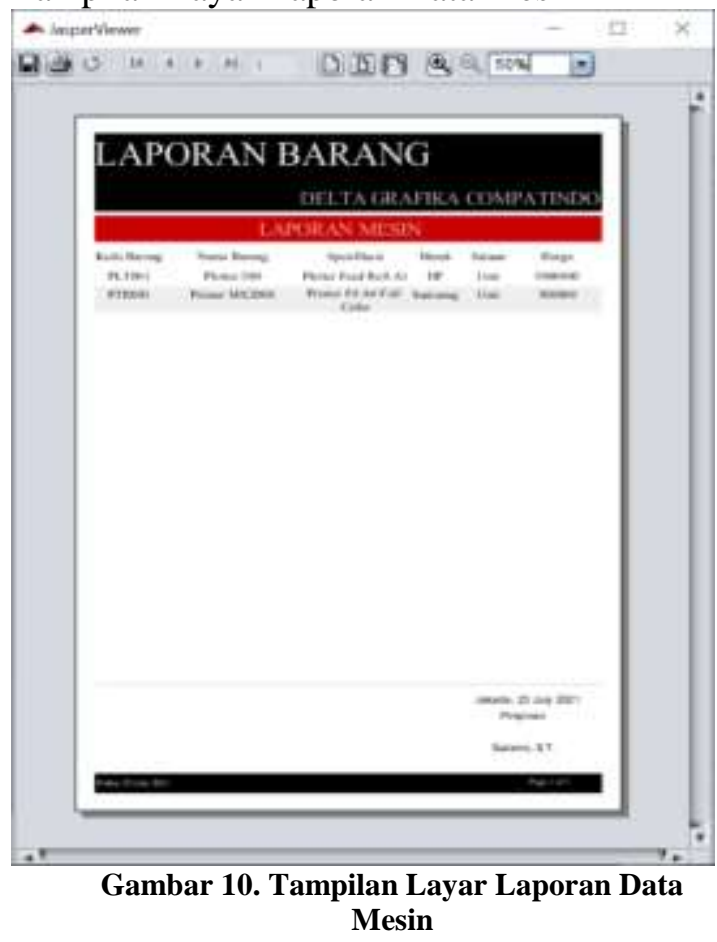

Laporan data mesin akan dicetak dan akan diserahkan kepada pimpinan sebagai laporan bulanan maupun tahunan.

Tampilan Layar Laporan Data Sparepart

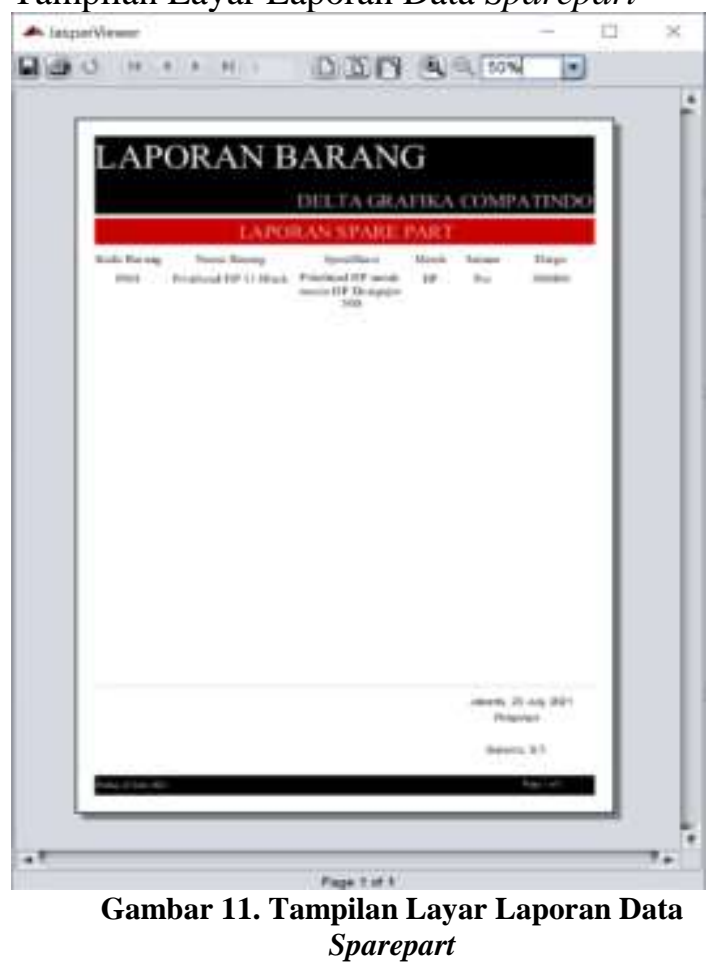

Laporan data sparepart akan dicetak dan akan diserahkan kepada pimpinan sebagai laporan bulanan maupun tahunan. 
Tampilan Layar Laporan Data Supplies

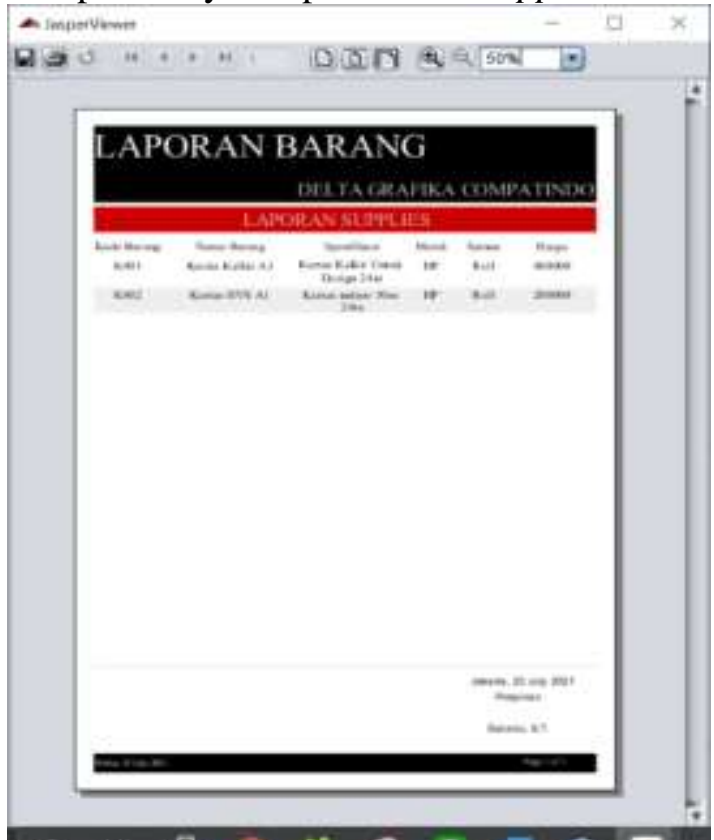

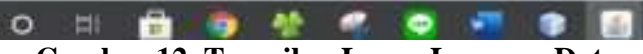
Gambar 12. Tampilan Layar Laporan Data Supplies

Di sini laporan data supplies akan dicetak dan akan diserahkan kepada pimpinan sebagai laporan bulanan maupun tahunan.

Tampilan Layar Laporan Penjualan

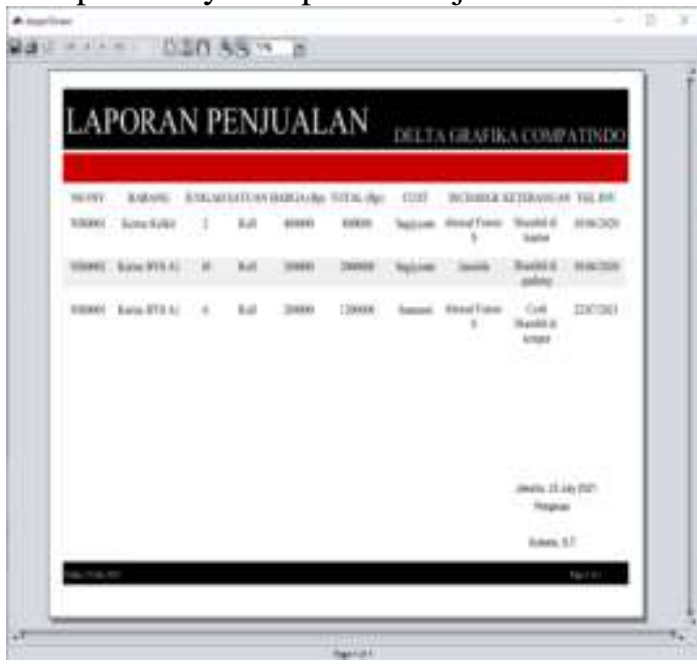

Gambar 13. Tampilan Layar Laporan Penjualan

Laporan penjualan sebagai rekapitulasi data barang yang terjual. Pelaporan nantinya akan ditujukan kepada pimpinan. Karyawan yang bertanggung jawab sudah tercantum dalam laporan.
Tampilan Layar Detail Penjualan

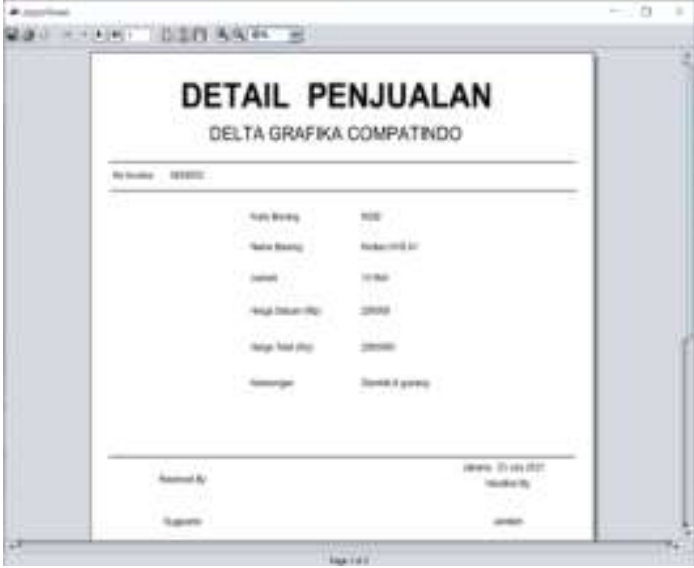

Gambar 14. Tampilan Layar Detail Penjualan

Detail penjualan membutuh tanda tangan karyawan dan customer sebagai invoice serta arsip bagi perusahaan.

Tampilan Layar Laporan Pembelian

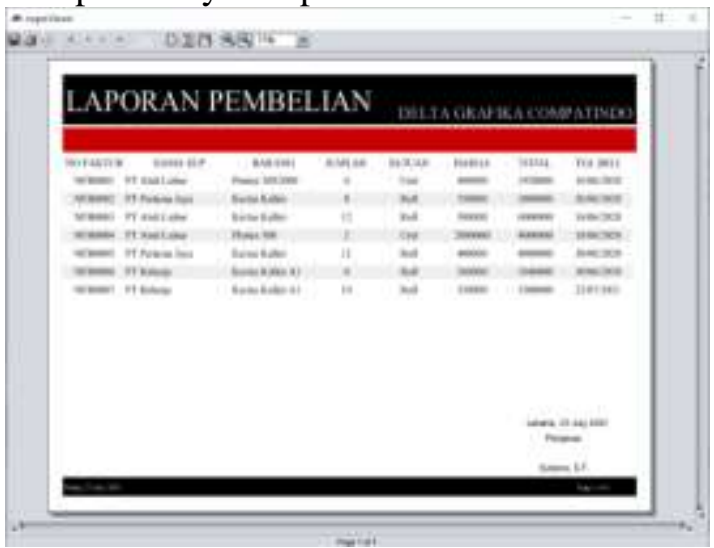

Gambar 15. Tampilan Layar Laporan Pembelian

Laporan pembelian ini digunakan sebagai rekapitulasi data pembelian barang dari beberapa supplier. Laporan akan diserahkan kepada pimpinan.

Tampilan Layar Detail Pembelian

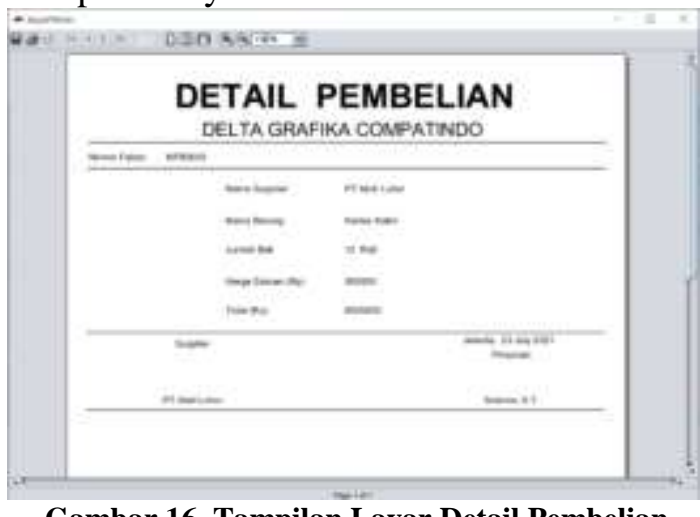

Gambar 16. Tampilan Layar Detail Pembelian 
Dokumen digunakan sebagai purchase order $(P O)$ yang ditujukan kepada pihak supplier dalam rangka permintaan barang. Dikirimkan melalui email serta validasi saat pengambilan barang.

\section{SIMPULAN DAN SARAN}

Peneliti memiliki simpulan sebagai berikut: Sistem aplikasi desktop persediaan sparepart dan supplies dibuat dengan bahasa pemrograman java dengan editor Netbeans 8.2. Data sparepart, supplies, supplier, dan customer sudah aman dalam database $M y S S Q L$. Data bisa digunakan dan diperbarui setiap saat dengan menggunakan aplikasi yang sudah dibuat.

Sistem aplikasi desktop persediaan sparepart dan supplies yang dibuat dapat meringankan pekerjaan karyawan dalam proses pembuatan laporan berkaitan dengan data laporan persediaan, pembelian, dan penjualan barang. Pembuatan laporan menjadi lebih efektif dan efisien.

Sejalan dengan sistem yang penulis buat, saran yang dapat diberikan adalah sebagai berikut: Pengisi spesifikasi sparepart dan supplies dapat mencari data pada internet dengan menggunakan serial number yang tertera jika sistem aplikasi dikelola oleh karyawan baru. Sistem aplikasi yang dihasilkan masih bisa dikembangkan lebih lanjut sehingga fitur-fitur yang ada bisa dilengkapi sesuai dengan kebutuhan perusahaan. Karena server lokasi database masih berada pada PC Komputer, akan lebih baik jika menggunakan cloud server agar data lebih aman.

Hasil penelitian ini selaras dengan hasil penelitian yang menyimpulkan bahwa aplikasi inventory mampu membantu meningkatkan efisiensi waktu saat memberikan informasi ketersediaan stok barang yang berada di gudang secara cepat dan akurat dan dapat meningkatkan efisiensi waktu dalam pencatatan persediaan barang masuk dan keluar secara update dan realtime. Selain itu, aplikasi inventory juga dapat membantu dalam mengurangi kerugian dari barang yang telah melewati batas tanggal kadaluwarsa (Zalukhu \& Handriani, 2019).

\section{UCAPAN TERIMAKASIH}

Terima kasih penulis ucapkan untuk pimpinan PT Delta Grafika Compatindo beserta karyawan yang telah memberikan izin dan bantuan sehingga penelitian ini terlaksana dengan baik.

\section{DAFTAR PUSTAKA}

Adhari, I. Z. (2020). Cara mudah bisnis percetakan yang kekinian. Jakad Media Publishing.

Hengki, S. S. (2017). Analisis dan perancangan sistem informasi inventory. Jurnal SISFOKOM, 06(2), 121-129.

Iskandar, A., Sudirman, A., Safitri, M., Sulaiman, O. K., Ramadhani, R., Wahyuni, D., Kurniawan, M. A., Mardiana, N., Jamaludin, J., Simarmata, J., \& others. (2020). Aplikasi pembelajaran berbasis TIK. Yayasan Kita Menulis.

Lubis, A. (2016). Basis data dasar. Deepublish.

Mamik. (2015). Metodologi kualitatif. Zifatama Publisher.

Muslihudin, M., \& others. (2016). Analisis dan perancangan sistem informasi menggunakan model terstruktur dan $U M L$. Penerbit Andi.

Ramadhani, A. R., Bunyamin, H., \& Fitriani, L. (2017). Perancangan aplikasi persediaan barang dan transaksi penjualan barang di Alya Store. Jurnal Algoritma, 13(2), 284-390. https://doi.org/10.33364/algoritma/v.13 $-2.384$

Stevenson, W. J., \& Chuong, S. C. (2013). Manajemen operasi perspektif asia (operations management an asian perspective) 1, E9. Salemba Empat.

Sukamto, R. A., \& Shalahuddin, M. (2011). Modul pembelajaran rekayasa perangkat lunak (terstruktur dan berorientasi objek). Modula.

Sutabri, T. (2012). Konsep sistem informasi. ANDI.

Yahfizham. (2019). Dasar-dasar komputer (M. S. Lubis (ed.)). Perdana.

Zalukhu, S., \& Handriani, I. (2019). Aplikasi sistem inventory (studi kasus : PT. Cakra Medika Utama). Jsai, 2(1), 116-122. 